\title{
Hallucinogens in Mental Health: Preclinical and Clinical Studies on LSD, Psilocybin, MDMA, and Ketamine
}

\author{
${ }^{\circledR}$ Danilo De Gregorio, ${ }^{1}{ }^{\circledR}$ Argel Aguilar-Valles, ${ }^{2 *}{ }^{\circledR}$ Katrin H. Preller, ${ }^{3 *}{ }^{\circledR}$ Boris Dov Heifets, ${ }^{4 *}$ Meghan Hibicke, ${ }^{5 *}$ \\ ${ }^{\circledR}$ Jennifer Mitchell, ${ }^{6 *}$ and ${ }^{\circledR}$ Gabriella Gobbi ${ }^{1}$ \\ ${ }^{1}$ Department of Psychiatry, McGill University, Montreal, Quebec H3A 1A1, Canada, ${ }^{2}$ Department of Neuroscience, Carleton University, Ottawa, \\ Ontario K1S 5B6, Canada, ${ }^{3}$ Department of Psychiatry, Psychotherapy and Psychosomatics, University of Zurich, CH-8032 Zurich, Switzerland, \\ ${ }^{4}$ Department of Psychiatry and Behavioral Sciences, Stanford University, Stanford, California 94305, ${ }^{5}$ Department of Pharmacology and \\ Experimental Therapeutics, Louisiana State University Health Sciences Center, New Orleans, Louisiana 70112, and ${ }^{6}$ Department of Neurology, \\ University of California San Francisco, San Francisco, California 94158
}

A revamped interest in the study of hallucinogens has recently emerged, especially with regard to their potential application in the treatment of psychiatric disorders. In the last decade, a plethora of preclinical and clinical studies have confirmed the efficacy of ketamine in the treatment of depression. More recently, emerging evidence has pointed out the potential therapeutic properties of psilocybin and LSD, as well as their ability to modulate functional brain connectivity. Moreover, MDMA, a compound belonging to the family of entactogens, has been demonstrated to be useful to treat post-traumatic stress disorders. In this review, the pharmacology of hallucinogenic compounds is summarized by underscoring the differences between psychedelic and nonpsychedelic hallucinogens as well as entactogens, and their behavioral effects in both animals and humans are described. Together, these data substantiate the potentials of these compounds in treating mental diseases.

Key words: hallucinogens; psychedelics; LSD; psilocybin; ketamine; MDMA

\section{Introduction}

Psychiatric disorders are a major public health concern affecting 350 million people and imposing social and economic burdens worldwide (Wittchen et al., 2011; Whiteford et al., 2013; Vigo et al., 2019). Despite tremendous efforts to uncover pathophysiological determinants, our understanding of psychiatric diseases and their treatment remains limited. After a long hiatus stemming from regulations that placed psychedelics in a restrictive regulated drug schedule (Belouin and Henningfield, 2018), investigation of these compounds is experiencing a renaissance in the research and clinical communities, especially with regard to their therapeutic application in mental disorders. Generally speaking, since the 1960s, hallucinogenic drugs have been classified into two groups: the "serotonergic classic hallucinogens" or "psychedelics," and the "dissociative anesthetics." Classic hallucinogens exert their pharmacological effects primarily through the 5-HT system, acting as agonists of the 5- $\mathrm{HT}_{2 \mathrm{~A}}$ receptor (Vollenweider et al., 2007; Passie et al., 2008; Vollenweider and Kometer, 2010). In contrast, "dissociative anesthetics," including ketamine, are considered to act on the

Received June 30, 2020; revised Sep. 29, 2020; accepted Oct. 9, 2020.

*A.A.-V., K.H.P., B.D.H., M.H., and J.M. contributed equally to this work.

This work was supported by the Quebec Network on Suicide, Mood Disorders and Related Disorders, and the Canadian Institute of Health Research to G.G. D.D.G. received fellowships from Fonds de la recherché du Quebec en Santé and the Canadian Institute of Health Research. B.D.H. was supported by National Institute on Mental Health Grant K08 MH110610 and Society for Neuroscience in Anesthesia and Critical Care.

Dr. Gabriella Gobbi is consultant at Diamond Therapeutics. Toronto (ON), Canada..

Correspondence should be addressed to Danilo De Gregorio at danilo.degregorio@mcgill.ca or Gabriella Gobbi at gabriella.gobbi@mcgill.ca.

https://doi.org/10.1523/JNEUROSCI.1659-20.2020

Copyright $\odot 2021$ the authors glutamatergic system and not on the 5-HT system, and they do not produce the same so-called "trip" as psychedelics, but are still considered hallucinogens (Vollenweider and Kometer, 2010). In the last decade, numerous studies in laboratory animals and humans have confirmed the usefulness of ketamine for the treatment of resistant depression. Research has also suggested potential antidepressant and mood-modulating properties of psilocybin and LSD, respectively, as well as the ability of these compounds to modulate functional brain connectivity (Carhart-Harris et al., 2016a, 2017). Other compounds, including 3,4-methylenedioxymethamphetamine (MDMA), are called entactogens. They produce psychotropic effects, but they do not share the same mechanism of action as hallucinogens (Kyzar et al., 2017). MDMA has been demonstrated to increase sociability in animals (Morley et al., 2005; Pitts et al., 2017; Curry et al., 2018; Heifets et al., 2019) and humans (Mithoefer et al., 2016) and to be useful in treating post-traumatic stress disorder (PTSD) (Mithoefer et al., 2011).

This review summarizes the pharmacological mechanism of psychedelics, nonpsychedelic hallucinogens, and entactogens as well as their impact on psychiatric research. In particular, we overview: (1) data on the effects of psychedelics in rodents and on brain functional connectivity in humans; (2) preclinical and clinical data on the antidepressant effects of ketamine; and (3) data on the prosocial effects of MDMA and its therapeutic applications in both animals and humans.

Psychedelics: the $5 \mathrm{HT}_{2 \mathrm{~A}}$ receptor

Psychedelics, also defined as "classic serotonergic hallucinogens" because they interact with the 5-HT system, are strongly involved 


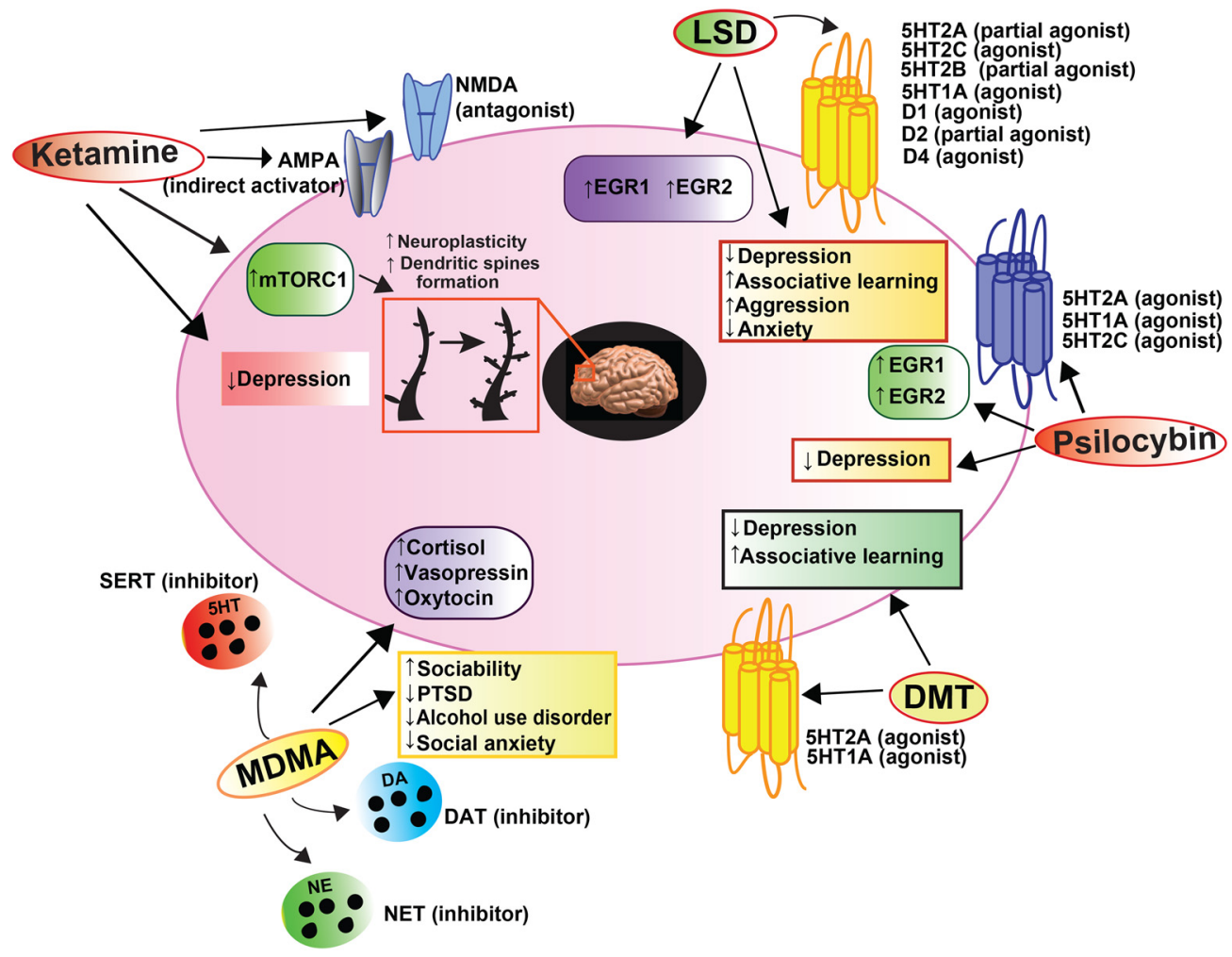

Figure 1. Schematic overview of the main pharmacological targets of LSD, psilocybin, DMT, MDMA, and ketamine, the signaling cascades involved, hormonal modulation, as well as main behavioral outcomes following their administration in both animals and humans. Abbreviations are reported in the main text.

in the treatment of psychiatric disorders, including depression (Meltzer, 1990), anxiety (Charney et al., 1990), and cognitive deficits (Meltzer et al., 2011). Psychedelics primarily act as $5-\mathrm{HT}_{2 \mathrm{~A}}$ receptor agonists, but their mechanism of action is more complex than originally thought. Indeed, psychedelics, including LSD, psilocin, psilocybin (a prodrug of psilocin), and N,N-dimethyltryptamine (DMT), have been demonstrated to also interact with $5 \mathrm{HT}_{1 \mathrm{~A}}, 5 \mathrm{HT}_{2 \mathrm{~B}}, 5 \mathrm{HT}_{2 \mathrm{C}}, 5 \mathrm{HT} 6$, and $5 \mathrm{HT} 7$ receptors (Passie et al., 2002, 2008; Nichols, 2004; Rickli et al., 2015; Wacker et al., 2017). Furthermore, a growing body of evidence demonstrates that both nonhallucinogenic (e.g., lisuride) and hallucinogenic $5-\mathrm{HT}_{2 \mathrm{~A}}$ agonists can activate intracellular signaling cascades in cortical pyramidal neurons, thus modulating downstream signaling proteins, including $\beta$-arrestin, early growth response protein 1 (EGR1), and EGR2 (González-Maeso et al., 2007; Schmid et al., 2008). Moreover, the activation of $5 \mathrm{HT}_{2 \mathrm{~A}}$ and $5 \mathrm{HT}_{1 \mathrm{~A}}$ receptors by LSD in the MPFC activates both the serotonergic and dopaminergic activity in the dorsal raphe nucleus and VTA, respectively. In particular, low doses of LSD (up to $30 \mu \mathrm{g} / \mathrm{kg}$ ) decrease the firing of 5-HT neurons without affecting the dopaminergic firing rate of VTA neurons, whereas higher doses $(40-60 \mu \mathrm{g} / \mathrm{kg})$ decrease the firing of dopaminergic VTA neurons (De Gregorio et al., 2016b). While the 5-HT system is implicated in mood and anxiety regulation, the dopaminergic system plays an important role in the mechanism of action of psychedelics (De Gregorio et al., 2016a, 2016b, 2018). Drug discrimination tasks in rodents revealed that the behavioral effects of LSD involve $5-\mathrm{HT}_{2 \mathrm{~A}}$ receptors in an initial phase, followed by a second phase that requires the dopamine $\mathrm{D}_{2}$ receptor (Marona-Lewicka et al., 2005). Furthermore, in vitro studies showed that LSD binds to the recombinant human $\mathrm{D}_{2}$ receptor in HEK 293 cells (Rickli et al., 2015, 2016). A similar experimental approach demonstrated that LSD also shows affinity for dopamine $\mathrm{D}_{1}$ (Rickli et al., 2015) and $\mathrm{D}_{4}$ (Passie et al., 2008) receptors. Finally, in vivo and in vitro evidence indicates a potential interaction of psychedelics, particularly LSD, with the trace amino associate receptor 1 (TAAR1) (Bunzow et al., 2001; De Gregorio et al., 2016b; Rickli et al., 2016), although more research is needed to understand the role of TAAR1 in the mechanism of action of psychedelics. A schematic representation of LSD, psilocybin, and DMT mechanism of action is shown in Figure 1.

Overall, psychedelic compounds display a pharmacological activity that goes beyond their action as $5 \mathrm{HT}_{2 \mathrm{~A}}$ agonist, and further investigations are needed to better elucidate their pleiotropic mechanisms of action (for a detailed discussion of the mechanism of action of psychedelics, see Passie et al., 2002, 2008; Nichols, 2016).

\section{Antidepressant effects of psychedelics: what can we learn from animal studies?}

There is evidence from studies in rodents that classic psychedelics, LSD (Buchborn et al., 2014; Hibicke et al., 2020), psilocin (Horsley et al., 2018), psilocybin (Hibicke et al., 2020), and DMT (Cameron et al., 2018, 2019), create long-term behavioral outcomes comparable to those of traditional antidepressant treatment in measures of coping strategy and cognitive function. Additionally, animal studies pointed out that psychedelics can enhance associative learning (Harvey, 2003; Buchborn et al., 2014), a cognitive function commonly impaired by neuropsychiatric disorders, particularly major depressive disorder (MDD) (Castaneda et al., 2008). However, a gold-standard protocol for assessing the behavioral effects of psychedelics has yet to be established, and a number of factors may confound the results, including which animal model and behavioral measures are used, as well as the kind of psychedelic drug tested. The literature 
addressing the effects of psychedelics on rodent behaviors relevant to psychiatric and cognitive function is sparse, and results of different studies may appear to align or to conflict with each other without being truly comparable. Dosing strategies must be taken into account. Whereas some studies have reported cognitive and/ or behavioral enhancements using chronic $(0.13 \mathrm{mg} / \mathrm{kg} /$ day LSD to male Wistar rats) (Buchborn et al., 2014) or intermittent dosing $(1 \mathrm{mg} / \mathrm{kg}$ DMT every third day to mixed sex Sprague Dawley rats) (Cameron et al., 2019), intermittent dosing ( $0.16 \mathrm{mg} / \mathrm{kg}$ LSD every other day) has been shown to dramatically decrease sociability and increase aggression in male SD rats (Marona-Lewicka et al., 2011). Further investigation found that a single dose of psilocybin $(1 \mathrm{mg} / \mathrm{kg})$ or LSD $(0.15 \mathrm{mg} / \mathrm{kg})$ profoundly affected longterm behavioral measures of male Wistar-Kyoto rats in a timeand context-dependent way (Hibicke et al., 2020). Time intervals between dosing and behavioral testing is another factor influencing the results of studies with psychedelics. While there is some evidence that acute DMT increases active coping strategies in the forced swim test (Cameron et al., 2018), psychedelics are not reliably rapid antidepressants (Hibicke et al., 2020), and antidepressant-like behavioral changes may not be measurable until 4 or more weeks after the psychedelic experience (Hibicke et al., 2020). As in humans, "set and setting" seems to play a role in the long-term behavioral outcome of rodents given psychedelics. Wistar-Kyoto rats given a single dose of psilocybin $(1 \mathrm{mg} / \mathrm{kg})$ then tested in the forced swim test at various time points between 1 and 5 weeks after administration, and in the elevated plus maze 6 weeks after administration, develop distinct behavioral responses depending on when they first encounter the forced swim test (Hibicke et al., 2020). Rats tested only once in the forced swim test (one swim, 5 weeks after psilocybin) were significantly and profoundly more likely to use active coping strategies (swimming/climbing) than a passive coping strategy (immobility) in that assay, but were not different from control rats in their elevated plus maze behavior a week later. However, rats tested in the forced swim test weekly for 5 weeks (five total swims), or 1 and 5 weeks (two swims) were only slightly (but significantly) more active in the forced swim test than control animals, and displayed significantly less anxiety-like behavior in the elevated plus maze 6 weeks after psilocybin (Hibicke et al., 2020).

One explanation for these differences is that psychedelic administration produces a period of behavioral flexibility in which new coping strategies can be learned. These animal studies suggest that psychedelic-assisted therapy may become a powerful tool for treating psychiatric and cognitive disorders, as the timing and the environmental context of administration are relevant for psychedelic therapeutics.

\section{What do psychedelics do to the human brain?}

The development of functional neuroimaging techniques has allowed researchers to better understand the impact of psychedelic drugs on brain connectivity patterns and on the activity of specific brain regions in humans. Alteration of information processing within cortico-striato-thalamo-cortical feedback loops is one mechanism suggested to underlie the psychedelic state (Vollenweider and Geyer, 2001; Geyer and Vollenweider, 2008). In healthy human participants, two neuroimaging studies confirmed that LSD induces increases in functional connectivity between the thalamus and sensory-somatomotor cortical regions (Muller et al., 2017; Preller et al., 2018). Additionally, LSD increased connectivity from the thalamus to the posterior cingulate cortex and concurrently decreased connectivity to the temporal cortex (Preller et al., 2019). These empirical results are in line with the cortico-striato-thalamo-cortical model; however, they do not support the hypothesis that LSD generates an undifferentiated increase in thalamocortical connectivity and information flow, but rather suggest a strengthening of specific connections between the thalamus and specific cortical areas. Data-driven approaches investigating the connectivity between each voxel of the brain have furthermore revealed that LSD and psilocybin increase interaction between sensory and somatomotor brain networks, and decrease communication among associative bran regions, including large scale brain-network, such as the Default Mode Network (Preller et al., 2018, 2020).

Together, these results suggest that increased processing of sensory information, potentially as a result of decreased thalamic gating, and concurrently reduced integration capacity because of diminished associative network integrity may underlie psychedelic experiences. It is possible that the altered integration of sensory perceptions facilitates a novel experience of the self and its environment and may help to reduce rigid or ruminative thinking patterns as observed in psychiatric disorders. However, this hypothesis still needs to be tested in clinical populations.

Additional studies investigating a priori hypotheses using seedbased imaging approaches have shown that subjective effects induced by psilocybin are associated with changes in the amplitude of low-frequency fluctuations and the variance of BOLD signal in the claustrum (Barrett et al., 2020a). Furthermore, this study showed that psilocybin decreased connectivity between the right claustrum and the auditory network and the Default Mode Network and concurrently increased connectivity with the frontoparietal control network (Barrett et al., 2020a). Additionally, changes in positive mood after a low dose of LSD were associated with increases in amygdala, frontal cortex connectivity (Bershad et al., 2019). Various other studies showed decreased connectivity between structures of the Default Mode Network after the administration of LSD, DMT, and psilocybin (Carhart-Harris et al., 2012, 2016b; Muthukumaraswamy et al., 2013; Palhano-Fontes et al., 2015; Muller et al., 2018; Preller et al., 2018). Finally, a prominent feature of psychedelics is alterations in visual perception. Those have repeatedly been associated with decreases in $\alpha$ oscillations, in particular over posterior parieto-occipital brain areas, suggesting that psychedelics increase the excitability of the visual pathway (Kometer et al., 2013; Schenberg et al., 2015; Valle et al., 2016; Pallavicini et al., 2019; Timmermann et al., 2019).

Neuroimaging studies investigating the effects of psychedelics in clinical populations with mental health conditions are still scarce. So far, it has been shown that treatment response measured 5 weeks after psilocybin treatment in patients with MDD was predicted by decreased connectivity between the PFC and the parahippocampus increased connectivity between the PFC and the inferior parietal cortex, $1 \mathrm{~d}$ after psilocybin administration. Furthermore, decreased amygdala cerebral blood flow correlated with reduced symptoms in the same study (Carhart-Harris et al., 2017). The same patients showed increased amygdala reactivity the morning after psilocybin and a reduction in amygdala, PFC connectivity in response to fearful faces (Roseman et al., 2018; Mertens et al., 2020). These results are surprising given that decreased amygdala reactivity and increased amygdala-PFC connectivity under the acute influence of psychedelics have been shown to correlate with positive mood in healthy participants (Kraehenmann et al., 2015; Mueller et al., 2017; Bershad et al., 2019). Furthermore, reduced amygdala reactivity in response to emotional stimuli was still present in healthy people 1 week after 
psilocybin administration (Barrett et al., 2020b), and this reduction has been hypothesized to be an important therapeutic mechanism because it may indicate that psychedelics normalize the negative cognitive bias observed in patients suffering from depression (Kraehenmann et al., 2015). It has to be noted, however, that increased amygdala reactivity in depressed patients was measured before any psychological or psychotherapeutic interventions aiming at integrating the psychedelic experience (Roseman et al., 2018). It is therefore conceivable that psilocybin facilitated the processing of negative life events, leading to markedly increased emotional processing and amygdala reactivity the morning after the session. Additional studies in clinical populations assessing long-term changes in brain activity and connectivity are necessary to clarify the mechanisms underlying the therapeutic effects of psychedelics.

\section{Ketamine, a fast-acting antidepressant acting through NMDA and mammalian target of rapamycin complex 1 (mTORC1)}

Ketamine is a dissociative anesthetic that marked a new era for the treatment of resistant MDD patients. Ketamine indeed produces fast antidepressant effects in both animal and humans at subanesthetic doses. Although ketamine does not appear to primarily target the serotonergic system, it is nonetheless capable of inducing psychedelic states (Dore et al., 2019). The antidepressant mechanism of action of ketamine remains the subject of intensive research. Ketamine is both a noncompetitive NMDAR, a glutamate receptor subtype broadly expressed in the CNS (Duman, 2018) antagonist, and an activator of the mTORC1 pathway (Workman et al., 2018; Zanos and Gould, 2018). Early studies in mice indicated that the NMDAR blocker, MK-801, and the competitive NMDAR inhibitor AP-7 decreased immobility time in the forced swim test, prompting the idea that NMDAR antagonism had antidepressant potential (Workman et al., 2018; Zanos and Gould, 2018). Despite the initial evidence in mice, NMDAR antagonism appears nonessential for ketamine's antidepressant action (Zanos and Gould, 2018). For example, other noncompetitive NMDAR antagonists, including memantine and MK-801, either lack antidepressant effects (e.g., memantine) or only have short-lasting effects, which are often inconsistent between studies (e.g., MK-801) (Zanos and Gould, 2018). This suggests that additional, non-NMDAR-mediated effects of ketamine mediate its striking antidepressant action, although the role of subtype specific binding to NMDRs of the different antagonists cannot be ruled out.

Consistent with this notion, chemical alteration of ketamine (via deuteration at the C6 position), which does not change its binding affinity for the NMDAR, but dramatically decreases its metabolism to a major metabolite $(2 \mathrm{~S}, 6 \mathrm{~S} ; 2 \mathrm{R}, 6 \mathrm{R})$-hydroxynorketamine (HNK) in vivo, nullifies ketamine's antidepressant actions in mice (Zanos et al., 2016). Furthermore, both HNK enantiomers [(2S,6S)- and (2R,6R)-HNK] exerted dose-dependent antidepressant actions in several rodent tests (Zanos et al., 2016; Yang et al., 2017; Pham et al., 2018). Interestingly, (2R,6R)-HNK, the enantiomer with the stronger antidepressant-like effects, is a less potent antagonist of NMDAR than ketamine itself (Moaddel et al., 2013; Zanos et al., 2016, 2017; Morris et al., 2017; Suzuki et al., 2017). Because of its reduced effects at the NMDAR, (2R,6R)HNK did not induce NMDAR inhibition-mediated side effects, such as sensorimotor dissociation (Zanos et al., 2016). However, $(2 \mathrm{R}, 6 \mathrm{R})-\mathrm{HNK}$ does not appear to be as potent as ketamine in relieving the behavioral changes induced by chronic social defeat in mice (Yang et al., 2017), suggesting the involvement of both
NMDAR-dependent and -independent pathways. Ketamine induces both synaptic and structural plasticity in the hippocampus, mPFC, and lateral habenula (Li et al., 2010, 2011; Yang et al., 2018b; Moda-Sava et al., 2019), involving signaling pathways that control protein synthesis (Li et al., 2010; Autry et al., 2011), such as the mTORC1 pathway. Indeed, increasing evidence suggests that activation of mTORC1 is a critical mechanism underlying the antidepressant action of ketamine and its metabolite (2R,6R)-HNK (Workman et al., 2018; Zanos and Gould, 2018). Numerous studies demonstrated that a single dose of ketamine and HNK induce a transient increase in phospho-mTOR and its targets, phospho-p70S6 kinase and phospho-4E-BP1, in the PFC and hippocampus of mice and rats (Li et al., 2010; Carrier and Kabbaj, 2013; Yang et al., 2013; Miller et al., 2014; Paul et al., 2014; Zhou et al., 2014; Zhang et al., 2017). More importantly, intracerebroventricular pretreatment with the allosteric mTORC1 inhibitor, rapamycin, blocked ketamine-induced synaptic molecular and behavioral effects relevant for antidepressant actions, including increased synaptic densities in the PFC, and decreased immobility in the forced swim test and latency to feed in the novelty suppressed feeding test (Li et al., 2010; Holubova et al., 2016; Yang et al., 2018a). mTORC1 controls numerous neuronal functions, including nucleotide and lipid synthesis, glucose metabolism, autophagy, lysosome biogenesis, proteasome assembly, and 5' cap-dependent mRNA translation (also known as protein synthesis) (Sonenberg and Hinnebusch, 2009; Saxton and Sabatini, 2017). Local dendritic translation of mRNA into protein is essential both for the homeostasis of synaptic function and for synaptic plasticity (Jung et al., 2014; Aguilar-Valles et al., 2018), which is thought to allow the brain to store information and display adaptive responses to subsequent related stimuli (Holtmaat and Svoboda, 2009; Duman et al., 2016). Key targets of the local activation of mRNA translation by ketamine are the AMPAR subunits, GluA1 and GluA2 (Workman et al., 2018). AMPARs mediate ketamine-induced synaptic facilitation in the mPFC and hippocampus (Li et al., 2010; Zanos et al., 2016; for review, see also Aleksandrova et al., 2017).

\section{Clinical perspectives of ketamine}

Ketamine's antidepressant properties have now been appreciated for almost two decades (Duman, 2018). Several placebo-controlled clinical trials have demonstrated the effectiveness of subanesthetic doses of ketamine $(0.5 \mathrm{mg} / \mathrm{kg}$, infused over $40 \mathrm{~min})$ for depression and suicidal ideation in MDD patients resistant to selective serotonin reuptake inhibitors (Berman et al., 2000; Zarate et al., 2006a; Price et al., 2009, 2014; DiazGranados et al., 2010; Ballard et al., 2014). In depressed patients, ketamine's defining features are its rapid therapeutic onset, measurable at 4 $h$, and its week-plus-long efficacy after a single infusion. Single infusions of ketamine are associated with a therapeutic response rate of $50 \%-70 \%$ at $1 \mathrm{~d}$ after treatment (Murrough et al., 2013b). Repeated treatments have the potential to sustain an antidepressant effect, although the overall response rate appears comparable to single-dose infusions (Murrough et al., 2013a; Singh et al., 2016), confirmed by recent results (Shiroma et al., 2020). In an open-label study, repeated injection of ketamine showed a decrease of $69 \%$ in suicidal ideation (Phillips et al., 2020). However, ketamine has significant abuse liability, and its long-term use is associated with notable bladder and neurologic toxicity (Schatzberg, 2014).

The physiological mechanisms for inducing and maintaining ketamine's lasting effects in humans are not yet understood well enough to design similar therapeutics with improved durability 
and safety. As previously explained, ketamine's antidepressant mechanism has long been attributed to antagonism of the NMDAR and to the activation of mTORC1. However, other NMDAR antagonists have failed to show clinical efficacy comparable to ketamine for MDD (Heresco-Levy et al., 2006; Zarate et al., 2006b; Sanacora et al., 2017; Wilkinson and Sanacora, 2019), suggesting that the mechanism of action of ketamine as an antidepressant is more complex than its action on NMDARs. More recently, clinical trials testing some of the predictions derived from NMDAR-based models have yielded unexpected results (Costi et al., 2019; Abdallah et al., 2020). Concerning the mTORC1 pathway, for example, a recent clinical study demonstrated that peripheral coadministration of rapamycin to treatment-resistant MDD patients enhanced, rather than blocked, the antidepressant effect of ketamine (Abdallah et al., 2020), suggesting a more complex interaction between these drugs in humans.

Nevertheless, the mTORC1 signaling pathway is downregulated in the hippocampus and PFC of MDD in postmortem tissue (Jernigan et al., 2011), consistent with this signaling pathway being relevant for the treatment of MDD. Other signaling systems, for example, opioid receptors (Williams et al., 2018), may also play a role, which is perhaps unsurprising in light of the diversity of ketamine's pharmacological targets. Shifting our perspective from receptor-based mechanisms to a neural-systems level analysis may provide new directions for optimizing ketamine therapy and developing novel treatments based on ketamine's mechanism.

Clinical studies are just beginning to map the similarities between ketamine and other psychedelic-assisted therapies. There is still significant debate regarding the role of the conscious subjective experience (typically described as "dissociation") that patients report during the subanesthetic ketamine infusion regimen. Some studies have linked ketamine's antidepressant potency to its dissociative effect (Zarate et al., 2006a; Monteggia and Kavalali, 2013; Niciu et al., 2018) and suggest that conscious awareness and sensory processing are crucial for ketamine's antidepressant effect (Dore et al., 2019). On the other hand, some clinical data suggest that dissociation is neither necessary (Leal et al., 2020) nor sufficient (Williams et al., 2018) to account for ketamine's efficacy. It is entirely possible that ketamine antidepressant therapy in a medicalized setting is functionally and mechanistically distinct from the emerging practice of ketamine-assisted psychotherapy (Dore et al., 2019).

\section{MDMA, a psychotropic drug with unique prosocial effects}

MDMA has emerged as a powerful adjunct to psychotherapy, with growing evidence for efficacy in the treatment of PTSD. This prototypical entactogen is an amphetamine derivative (Nichols, 1986), which primarily releases supraphysiological levels of serotonin, dopamine, and norepinephrine via their respective reuptake transporters (SERT, DAT, and NET) (Rothman and Baumann, 2002; Green et al., 2003; Gudelsky and Yamamoto, 2008). MDMA also stimulates the release of hormones, including oxytocin, vasopressin, and cortisol (Green et al., 2003; Kamilar-Britt and Bedi, 2015). A schematic representation of the mechanism of MDMA is shown in Figure 1. For many years, animal studies of MDMA focused on MDMA-associated neurotoxicity, hyperthermia, psychostimulant effects, and abuse potential, none of which are obviously related to its therapeutic mechanism (Green et al., 2003). While MDMA's therapeutic mechanism is not fully understood, clinical experience indicates that long-lasting benefits are more likely to occur when it is used as an adjunct to psychotherapy rather than as a stand-alone therapy (Greer and Tolbert, 1986; Grinspoon and Bakalar, 1986). Widespread adoption of MDMA-assisted psychotherapy may be limited by MDMA's potential for abuse and an incompatibility with selective serotonin reuptake inhibitors (Heifets and Malenka, 2019). Improving on MDMA as a psychotherapeutic adjunct requires a deeper understanding of the pharmacology and neural dynamics underlying MDMA's therapeutic effect in humans.

Toward this end, recent work in rodents has modeled distinct behavioral processes hypothesized to play a role in MDMAassisted psychotherapy. MDMA's hallmark effect is an acutely enhanced feeling of openness, trust, and social connection, all of which may serve to enhance the therapeutic alliance (Mithoefer et al., 2016). Similarly, in several species (Morley et al., 2005; Pitts et al., 2017; Curry et al., 2018; Heifets et al., 2019), MDMA can produce an array of affiliative and prosocial behaviors. MDMA may also modify the sensitivity to social reward in mice, an effect lasting weeks after a single dose (Nardou et al., 2019), reminiscent of the "integration therapy" process after an MDMA experience, wherein a patient is encouraged to consider how emotional shifts in the aftermath of their MDMA session may be integrated into daily life (Greer and Tolbert, 1986). Finally, MDMA disrupts fear memories in a widely used model for PTSD (Young et al., 2015, 2017; Hake et al., 2019), wherein a conditioned fear memory is extinguished by re-cueing the memory in a safe context.

Investigators consistently find that SERT-mediated 5-HT release is necessary (Young et al., 2017; Heifets et al., 2019; Nardou et al., 2019), and potentially sufficient (Walsh et al., 2018), to account for the putative therapeutic mechanisms of MDMA. Notably, these models' differences could inform human mechanistic trials. Fear extinction does not involve any particular social context, and mouse data suggest that 5-HT release in basolateral amygdala fully accounts for MDMA's effect on fear memory (Young et al., 2015). In contrast, social behavioral models find that 5-HT release in the nucleus accumbens explains MDMA's effects (Walsh et al., 2018; Heifets et al., 2019; Nardou et al., 2019). Various 5-HT receptor subtypes appear necessary (Heifets et al., 2019; Nardou et al., 2019), although it is unclear whether any one subtype's activity can reproduce MDMA's prosocial effects. Finally, although MDMA and oxytocin actions overlap (Dölen et al., 2013; Kamilar-Britt and Bedi, 2015; Nardou et al., 2019), available data in rodents (Ramos et al., 2016; Heifets et al., 2019) and humans (Kamilar-Britt and Bedi, 2015) suggest that oxytocin receptor signaling is not required for MDMA's acute prosocial effects, but may be involved in longerterm processes initiated by MDMA effects (Nardou et al., 2019). These studies make clear predictions that it can be tested in clinical experiments, the results of which will both refine our understanding of how clinical MDMA therapy works and improve the accuracy of preclinical models.

\section{MDMA in clinical studies}

MDMA was first administered clinically in the 1970s (Shulgin, 1978), at which time there was speculation that the drug acted to "fortify the therapeutic alliance by inviting self-disclosure and enhancing trust" (Grinspoon and Bakalar, 1986). A series of small, uncontrolled studies followed, which together suggested that MDMA was an effective adjunct to psychotherapy, especially in those suffering from anxiety (Greer and Tolbert, 1986; Grinspoon and Bakalar, 1986). Research was halted when MDMA was placed on the DEA Schedule 1 list in 1985, and scientific assessment of 
the compound's therapeutic efficacy did not resume until the mid-1990s (Nutt et al., 2013). A Phase 1 dose-finding and safety study in MDMA-experienced subjects was conducted shortly thereafter (Grob et al., 1996) and suggested that a range of doses (0.25-1.0 mg/kg, p.o.) could safely be administered with minimal side effects. More recent data have shown that MDMA commonly induces side effects that include teeth grinding, jaw clenching, headache, lack of appetite, fatigue, dizziness, and nausea but that these are most often mild to moderate and resolve without assistance and shortly after treatment (Mithoefer et al., 2011). Additional Phase 1 data are currently being collected (Psychological Effects of Methylenedioxymethamphetamine (MDMA) When Administered to Healthy Volunteers, 2020). While there had been previous concern over the potentially toxic effects of MDMA (Ricaurte et al., 2002), the paper reporting widespread dopaminergic and serotonergic neurotoxicity in nonhuman primates turned out to be deeply flawed and was eventually retracted (Ricaurte et al., 2003).

Early human data indicate that MDMA could be particularly useful in assisting emotional processing and, therefore, recovery in people suffering from PTSD (Sessa, 2011). The first randomized and controlled pilot study found that either two or three administrations of MDMA enabled a significant and long-lasting reduction in PTSD symptoms (Mithoefer et al., 2011). Perhaps most intriguing, not only were the effects of MDMA on PTSD symptomology robust, but they also appeared to be extremely durable, lasting for at least 1 year after treatment (Mithoefer et al., 2013). Approximately one dozen Phase 2 studies have now been conducted using MDMA in populations with severe, treatment-resistant PTSD, and the results have been consistently encouraging. Pooled analysis from six of these Phase 2 clinical trials (Mithoefer et al., 2019) enabled the FDA to grant Breakthrough Therapy status for MDMA treatment of PTSD and has facilitated the initiation of a Phase 3 clinical trial (Multidisciplinary Association for Psychedelic Studies, 2018). A randomized, double-blind, placebo-controlled, Phase 3 study of MDMA-assisted psychotherapy for the treatment of severe PTSD is currently in progress (Multi-Site Phase 3 Study of MDMAAssisted Psychotherapy for PTSD, 2020). The open-label lead-in data from this Phase 3 trial have shown that MDMA significantly and robustly attenuates several of the prototypical symptoms of PTSD (J. Mitchell, unpublished data). While we must still await final analyses and publication of Phase 3 data, the early trial data suggest that MDMA, in conjunction with psychotherapy, may be a fruitful therapeutic for several complex treatment populations, which lends further credence to the theory that psychedelic medicines could prove to be rapid, long-lasting, novel therapeutics for mental health disorders.

Recent data suggest that MDMA may also be efficacious in other clinical populations, including people with autism spectrum disorder (Danforth et al., 2018) and with alcohol use disorder (Sessa, 2018). With respect to alcohol use disorder, safety and tolerability data from a pilot population have already been published (Sessa et al., 2019), and a Phase 2 clinical trial designed to evaluate changes in alcohol use disorder is currently underway (Bristol Imperial MDMA in Alcoholism Study, 2020). Although therapeutic facilitation has been shown to clearly influence treatment outcome (Mithoefer et al., 2016; Krediet et al., 2020), more research must still be conducted to determine which therapeutic interaction works best for different clinical populations. Furthermore, although context is known to be an important variable in the therapeutic impact of psychedelics (Carhart-Harris et al., 2018), little work has been conducted to date to unravel the complicated interaction between set and setting and MDMA treatment outcome.

In conclusion, in this review, we offered an overview of how different hallucinogens may produce distinct behavioral outcomes with different molecular and neuronal mechanisms of action. All these psychoactive drugs can cause subjective changes in perception, thought, emotion, and consciousness, although with a different mechanism. From preclinical studies, it is clear that the mechanism of hallucinogens is more complex than thought before since their effects on the 5-HT and glutamatergic system as well as their capacity to modulate transcriptional mechanisms seem to emerge very clearly (for review, see Inserra et al., 2021). Importantly, clinical studies have demonstrated the effects of ketamine in treatment-resistant MDD (Marcantoni et al., 2020). Moreover, a double-blind, placebo-controlled clinical trial has shown the use of MDMA associated to psychotherapy in PTSD (Mithoefer et al., 2019). In addition, open-label studies and double-blind studies have demonstrated the effects of psylocibin in depression and anxiety, even if a recent meta-analysis suggests that more studies are needed to demonstrate its efficacy (Goldberg et al., 2020). Intriguingly, the potential use of psilocybin in alcohol use disorder and obsessive-compulsive disorder seems also promising, and several clinical trials are ongoing (Clinical and Mechanistic Effects of Psilocybin in Alcohol Addicted Patients, 2020; Efficacy of Psilocybin in OCD: a Double-Blind, PlaceboControlled Study, 2020).

Finally, LSD showed promising results in patients with depression and anxiety (Gasser et al., 2014, 2015), and clinical trials are ongoing for MDD (for review, see Inserra et al., 2020). Along with the potential use of hallucinogenic compounds in the clinic, it is undeniable that they also represent an important tool to better understand the neuronal circuitries, brain connectivity, pharmacological targets, and signaling cascades behind the pathology of mental disorders.

\section{References}

Abdallah CG, Averill LA, Gueorguieva R, Goktas S, Purohit P, Ranganathan M, Sherif M, Ahn KH, D'Souza DC, Formica R, Southwick SM, Duman RS, Sanacora G, Krystal JH (2020) Modulation of the antidepressant effects of ketamine by the mTORC1 inhibitor rapamycin. Neuropsychopharmacology 45:990-997.

Aguilar-Valles A, Matta-Camacho E, Sonenberg N, (2018) Translational control through the eIF4E binding proteins in the brain. In: The Oxford handbook of neuronal protein synthesis (Sossin W, ed). Oxford: Oxford UP.

Aleksandrova LR, Phillips AG, Wang YT (2017) Antidepressant effects of ketamine and the roles of AMPA glutamate receptors and other mechanisms beyond NMDA receptor antagonism. J Psychiatry Neurosci 42:222-229.

Autry AE, Adachi M, Nosyreva E, Na ES, Los MF, Cheng PF, Kavalali ET, Monteggia LM (2011) NMDA receptor blockade at rest triggers rapid behavioural antidepressant responses. Nature 475:91-95.

Ballard ED, Ionescu DF, Vande Voort JL, Niciu MJ, Richards EM, Luckenbaugh DA, Brutsche NE, Ameli R, Furey ML, Zarate CA Jr (2014) Improvement in suicidal ideation after ketamine infusion: relationship to reductions in depression and anxiety. J Psychiatr Res 58:161-166.

Barrett FS, Krimmel SR, Griffiths R, Seminowicz DA, Mathur BN (2020a) Psilocybin acutely alters the functional connectivity of the claustrum with brain networks that support perception, memory, and attention. Neuroimage 218:116980.

Barrett FS, Doss MK, Sepeda ND, Pekar JJ, Griffiths RR (2020b) Emotions and brain function are altered up to one month after a single high dose of psilocybin. Sci Rep 10:2214.

Belouin SJ, Henningfield JE (2018) Psychedelics: where we are now, why we got here, what we must do. Neuropharmacology 142:7-19. 
Berman RM, Cappiello A, Anand A, Oren DA, Heninger GR, Charney DS, Krystal JH (2000) Antidepressant effects of ketamine in depressed patients. Biol Psychiatry 47:351-354.

Bershad AK, Preller KH, Lee R, Keedy S, Wren-Jarvis J, Bremmer MP, de Wit H (2019) Preliminary report on the effects of a low dose of LSD on resting-state amygdala functional connectivity. Biol Psychiatry Cogn Neurosci Neuroimaging 5:461-467.

Bristol Imperial MDMA in Alcoholism Study (2020) https://clinicaltrials.gov/ ct $2 /$ show/NCT04158778?term=mdma\&cond=Alcohol + Use + Disorder \& draw $=2$ \&rank $=1$.

Buchborn T, Schröder H, Höllt V, Grecksch G (2014) Repeated lysergic acid diethylamide in an animal model of depression: normalisation of learning behaviour and hippocampal serotonin 5-HT2 signalling. J Psychopharmacol 28:545-552.

Bunzow JR, Sonders MS, Arttamangkul S, Harrison LM, Zhang G, Quigley DI, Darland T, Suchland KL, Pasumamula S, Kennedy JL, Olson SB, Magenis RE, Amara SG, Grandy DK (2001) Amphetamine, 3,4-methylenedioxymethamphetamine, lysergic acid diethylamide, and metabolites of the catecholamine neurotransmitters are agonists of a rat trace amine receptor. Mol Pharmacol 60:1181-1188.

Cameron LP, Benson CJ, Dunlap LE, Olson DE (2018) Effects of N,N-dimethyltryptamine on rat behaviors relevant to anxiety and depression. ACS Chem Neurosci 9:1582-1590.

Cameron LP, Benson CJ, DeFelice BC, Fiehn O, Olson DE (2019) Chronic, intermittent microdoses of the psychedelic N,N-dimethyltryptamine (DMT) produce positive effects on mood and anxiety in rodents. ACS Chem Neurosci 10:3261-3270.

Carhart-Harris RL, Erritzoe D, Williams T, Stone JM, Reed LJ, Colasanti A, Tyacke RJ, Leech R, Malizia AL, Murphy K, Hobden P, Evans J, Feilding A, Wise RG, Nutt DJ (2012) Neural correlates of the psychedelic state as determined by fMRI studies with psilocybin. Proc Natl Acad Sci USA 109:2138-2143.

Carhart-Harris RL, Bolstridge M, Rucker J, Day CM, Erritzoe D, Kaelen M, Bloomfield M, Rickard JA, Forbes B, Feilding A, Taylor D, Pilling S, Curran VH, Nutt DJ (2016a) Psilocybin with psychological support for treatment-resistant depression: an open-label feasibility study. Lancet Psychiatry 3:619-627.

Carhart-Harris RL, Muthukumaraswamy S, Roseman L, Kaelen M, Droog W, Murphy K, Tagliazucchi E, Schenberg EE, Nest T, Orban C, Leech R, Williams LT, Williams TM, Bolstridge M, Sessa B, McGonigle J, Sereno MI, Nichols D, Hellyer PJ, Hobden P, et al. (2016b) Neural correlates of the LSD experience revealed by multimodal neuroimaging. Proc Natl Acad Sci USA 113:4853-4858

Carhart-Harris RL, Roseman L, Bolstridge M, Demetriou L, Pannekoek JN, Wall MB, Tanner M, Kaelen M, McGonigle J, Murphy K, Leech R, Curran HV, Nutt DJ (2017) Psilocybin for treatment-resistant depression: fMRI-measured brain mechanisms. Sci Rep 7:13187.

Carhart-Harris RL, Roseman L, Haijen E, Erritzoe D, Watts R, Branchi I, Kaelen M (2018) Psychedelics and the essential importance of context. J Psychopharmacol 32:725-731.

Carrier N, Kabbaj M (2013) Sex differences in the antidepressant-like effects of ketamine. Neuropharmacology 70:27-34.

Castaneda AE, Tuulio-Henriksson A, Marttunen M, Suvisaari J, Lönnqvist J (2008) A review on cognitive impairments in depressive and anxiety disorders with a focus on young adults. J Affect Disord 106:1-27.

Charney DS, Woods SW, Krystal JH, Heninger GR (1990) Serotonin function and human anxiety disorders. Ann NY Acad Sci 600:558-572.

Clinical and Mechanistic Effects of Psilocybin in Alcohol Addicted Patients (2020) https://clinicaltrials.gov/ct2/show/NCT04141501?term=psilocybin\& cond $=$ Alcohol-Related + Disorders\&draw $=2 \&$ rank $=3$.

Costi S, Soleimani L, Glasgow A, Brallier J, Spivack J, Schwartz J, Levitch CF, Richards S, Hoch M, Wade E, Welch A, Collins KA, Feder A, Iosifescu DV, Charney DS, Murrough JW (2019) Lithium continuation therapy following ketamine in patients with treatment resistant unipolar depression: a randomized controlled trial. Neuropsychopharmacology 44:18121819.

Curry DW, Young MB, Tran AN, Daoud GE, Howell LL (2018) Separating the agony from ecstasy: R(-)-3,4-methylenedioxymethamphetamine has prosocial and therapeutic-like effects without signs of neurotoxicity in mice. Neuropharmacology 128:196-206.

Danforth AL, Grob CS, Struble C, Feduccia AA, Walker N, Jerome L, YazarKlosinski B, Emerson A (2018) Reduction in social anxiety after MDMA- assisted psychotherapy with autistic adults: a randomized, double-blind, placebo-controlled pilot study. Psychopharmacology (Berl) 235:31373148.

De Gregorio D, Comai S, Posa L, Gobbi G (2016a) d-Lysergic acid diethylamide (LSD) as a model of psychosis: mechanism of action and pharmacology. Int J Mol Sci 17:1953

De Gregorio D, Posa L, Ochoa-Sanchez R, McLaughlin R, Maione S, Comai S, Gobbi G (2016b) The hallucinogen d-lysergic diethylamide (LSD) decreases dopamine firing activity through 5-HT1A, D2 and TAAR1 receptors. Pharmacol Res 113:81-91.

De Gregorio D, Enns JP, Nuñez NA, Posa L, Gobbi G (2018) d-Lysergic acid diethylamide, psilocybin, and other classic hallucinogens: mechanism of action and potential therapeutic applications in mood disorders. In: Progress in brain research, pp 69-96. Amsterdam: Elsevier.

DiazGranados N, Ibrahim LA, Brutsche NE, Ameli R, Henter ID, Luckenbaugh DA, Machado-Vieira R, Zarate CA Jr (2010) Rapid resolution of suicidal ideation after a single infusion of an N-methyl-D-aspartate antagonist in patients with treatment-resistant major depressive disorder. J Clin Psychiatry 71:1605-1611.

Dölen G, Darvishzadeh A, Huang KW, Malenka RC (2013) Social reward requires coordinated activity of nucleus accumbens oxytocin and serotonin. Nature 501:179-184.

Dore J, Turnipseed B, Dwyer S, Turnipseed A, Andries J, Ascani G, Monnette C, Huidekoper A, Strauss N, Wolfson P (2019) Ketamine assisted psychotherapy (KAP): patient demographics, clinical data and outcomes in three large practices administering ketamine with psychotherapy. J Psychoactive Drugs 51:189-198.

Duman RS (2018) Ketamine and rapid-acting antidepressants: a new era in the battle against depression and suicide. F1000Res 7:659.

Duman RS, Aghajanian GK, Sanacora G, Krystal JH (2016) Synaptic plasticity and depression: new insights from stress and rapid-acting antidepressants. Nat Med 22:238-249.

Efficacy of Psilocybin in OCD: a Double-Blind, Placebo-Controlled Study (2020) https://clinicaltrials.gov/ct2/show/NCT03356483?term=psilocybin\& cond $=$ Obsessive-Compulsive + Disorder \&draw $=2 \&$ rank $=2$.

Gasser P, Holstein D, Michel Y, Doblin R, Yazar-Klosinski B, Passie T, Brenneisen R (2014) Safety and efficacy of lysergic acid diethylamideassisted psychotherapy for anxiety associated with life-threatening diseases. J Nerv Ment Dis 202:513-520.

Gasser P, Kirchner K, Passie T (2015) LSD-assisted psychotherapy for anxiety associated with a life-threatening disease: a qualitative study of acute and sustained subjective effects. J Psychopharmacol 29:57-68

Geyer MA, Vollenweider FX (2008) Serotonin research: contributions to understanding psychoses. Trends Pharmacol Sci 29:445-453.

Goldberg SB, Pace BT, Nicholas CR, Raison CL, Hutson PR (2020) The experimental effects of psilocybin on symptoms of anxiety and depression: a meta-analysis. Psychiatry Res 284:112749.

González-Maeso J, Weisstaub NV, Zhou M, Chan P, Ivic L, Ang R, Lira A, Bradley-Moore M, Ge Y, Zhou Q, Sealfon SC, Gingrich JA (2007) Hallucinogens recruit specific cortical 5-HT2A receptor-mediated signaling pathways to affect behavior. Neuron 53:439-452.

Green AR, Mechan AO, Elliott JM, O'Shea E, Colado MI (2003) The pharmacology and clinical pharmacology of 3,4-methylenedioxymethamphetamine (MDMA, "ecstasy"). Pharmacol Rev 55:463-508.

Greer G, Tolbert R (1986) Subjective reports of the effects of MDMA in a clinical setting. J Psychoactive Drugs 18:319-327.

Grinspoon L, Bakalar JB (1986) Can drugs be used to enhance the psychotherapeutic process? Am J Psychother 40:393-404.

Grob CS, Poland RE, Chang L, Ernst T (1996) Psychobiologic effects of 3,4methylenedioxymethamphetamine in humans: methodological considerations and preliminary observations. Behav Brain Res 73:103-107.

Gudelsky GA, Yamamoto BK (2008) Actions of 3,4-methylenedioxymethamphetamine (MDMA) on cerebral dopaminergic, serotonergic and cholinergic neurons. Pharmacol Biochem Behav 90:198-207.

Hake HS, Davis JK, Wood RR, Tanner MK, Loetz EC, Sanchez A, Ostrovskyy M, Oleson EB, Grigsby J, Doblin R, Greenwood BN (2019) 3,4-Methylenedioxymethamphetamine (MDMA) impairs the extinction and reconsolidation of fear memory in rats. Physiol Behav 199:343-350.

Harvey JA (2003) Role of the serotonin 5-HT2A receptor in learning. Learn Mem 10:355-362.

Heifets BD, Malenka RC (2019) Disruptive psychopharmacology. JAMA Psychiatry 76:775-776. 
Heifets BD, Salgado JS, Taylor MD, Hoerbelt P, Pinto DF, Steinberg EE, Walsh JJ, Sze JY, Malenka RC (2019) Distinct neural mechanisms for the prosocial and rewarding properties of MDMA. Sci Transl Med 11: eaaw6435

Heresco-Levy U, Javitt DC, Gelfin Y, Gorelik E, Bar M, Blanaru M, Kremer I (2006) Controlled trial of D-cycloserine adjuvant therapy for treatmentresistant major depressive disorder. J Affect Disord 93:239-243.

Hibicke M, Landry AN, Kramer HM, Talman ZK, Nichols CD (2020) Psychedelics, but not ketamine, produce persistent antidepressant-like effects in a rodent experimental system for the study of depression. ACS Chem Neurosci 11:864-871.

Holtmaat A, Svoboda K (2009) Experience-dependent structural synaptic plasticity in the mammalian brain. Nat Rev Neurosci 10:647-658.

Holubova K, Kleteckova L, Skurlova M, Ricny J, Stuchlik A, Vales K (2016) Rapamycin blocks the antidepressant effect of ketamine in task-dependent manner. Psychopharmacology (Berl) 233:2077-2097.

Horsley RR, Páleníček T, Kolin J, Valeš K (2018) Psilocin and ketamine microdosing: effects of subchronic intermittent microdoses in the elevated plus-maze in male Wistar rats. Behavioural pharmacology 29:530536.

Inserra A, De Gregorio D, Gobbi G (2021) Psychedelics in psychiatry: neuroplastic, immunomodulatory, and neurotransmitter mechanisms. Pharmacol Rev 73:1-77.

Jernigan CS, Goswami DB, Austin MC, Iyo AH, Chandran A, Stockmeier CA, Karolewicz B (2011) The mTOR signaling pathway in the prefrontal cortex is compromised in major depressive disorder. Prog Neuropsychopharmacol Biol Psychiatry 35:1774-1779.

Jung H, Gkogkas CG, Sonenberg N, Holt CE (2014) Remote control of gene function by local translation. Cell 157:26-40.

Kamilar-Britt P, Bedi G (2015) The prosocial effects of 3,4-methylenedioxymethamphetamine (MDMA): controlled studies in humans and laboratory animals. Neurosci Biobehav Rev 57:433-446.

Kometer M, Schmidt A, Jancke L, Vollenweider FX (2013) Activation of serotonin $2 \mathrm{~A}$ receptors underlies the psilocybin-induced effects on alpha oscillations, N170 visual-evoked potentials, and visual hallucinations. J Neurosci 33:10544-10551.

Kraehenmann R, Preller KH, Scheidegger M, Pokorny T, Bosch OG, Seifritz E, Vollenweider FX (2015) Psilocybin-induced decrease in amygdala reactivity correlates with enhanced positive mood in healthy volunteers. Biol Psychiatry 78:572-581.

Krediet E, Bostoen T, Breeksema J, van Schagen A, Passie T, Vermetten E (2020) Reviewing the potential of psychedelics for the treatment of PTSD. Int J Neuropsychopharmacol 23:385-400.

Kyzar EJ, Nichols CD, Gainetdinov RR, Nichols DE, Kalueff AV (2017) Psychedelic drugs in biomedicine. Trends Pharmacol Sci 38:992-1005.

Leal GC, Bandeira ID, Correia-Melo FS, Telles M, Mello RP, Vieira F, Lima CS, Jesus-Nunes AP, Guerreiro-Costa LN, Marback RF (2020) Intravenous arketamine for treatment-resistant depression: open-label pilot study. Eur Arch Psychiatry Clin Neurosci. Advance online publication. Retrieved Feb 20, 2020.

Li N, Lee B, Liu RJ, Banasr M, Dwyer JM, Iwata M, Li XY, Aghajanian G, Duman RS (2010) mTOR-dependent synapse formation underlies the rapid antidepressant effects of NMDA antagonists. Science 329:959-964.

Li N, Liu RJ, Dwyer JM, Banasr M, Lee B, Son H, Li XY, Aghajanian G, Duman RS (2011) Glutamate N-methyl-D-aspartate receptor antagonists rapidly reverse behavioral and synaptic deficits caused by chronic stress exposure. Biol Psychiatry 69:754-761.

Marcantoni WS, Akoumba BS, Wassef M, Mayrand J, Lai H, RichardDevantoy S, Beauchamp S (2020) A systematic review and meta-analysis of the efficacy of intravenous ketamine infusion for treatment resistant depression: January 2009-January 2019. J Affect Disord 277:831-841.

Marona-Lewicka D, Thisted RA, Nichols DE (2005) Distinct temporal phases in the behavioral pharmacology of LSD: dopamine D2 receptor-mediated effects in the rat and implications for psychosis. Psychopharmacology (Berl) 180:427-435

Marona-Lewicka D, Nichols CD, Nichols DE (2011) An animal model of schizophrenia based on chronic LSD administration: old idea, new results. Neuropharmacology 61:503-512.

Meltzer HY (1990) Role of serotonin in depression. Ann NY Acad Sci 600:486-499.
Meltzer HY, Horiguchi M, Massey BW (2011) The role of serotonin in the NMDA receptor antagonist models of psychosis and cognitive impairment. Psychopharmacology (Berl) 213:289-305.

Mertens LJ, Wall MB, Roseman L, Demetriou L, Nutt DJ, Carhart-Harris RL (2020) Therapeutic mechanisms of psilocybin: changes in amygdala and prefrontal functional connectivity during emotional processing after psilocybin for treatment-resistant depression. J Psychopharmacol 34:167180

Miller OH, Yang L, Wang CC, Hargroder EA, Zhang Y, Delpire E, Hall BJ (2014) GluN2B-containing NMDA receptors regulate depression-like behavior and are critical for the rapid antidepressant actions of ketamine. Elife 3:e03581.

Mithoefer MC, Wagner MT, Mithoefer AT, Jerome L, Doblin R (2011) The safety and efficacy of $\{+/-\} 3,4$-methylenedioxymethamphetamineassisted psychotherapy in subjects with chronic, treatment-resistant posttraumatic stress disorder: the first randomized controlled pilot study. J Psychopharmacol 25:439-452.

Mithoefer MC, Wagner MT, Mithoefer AT, Jerome L, Martin SF, YazarKlosinski B, Michel Y, Brewerton TD, Doblin R (2013) Durability of improvement in post-traumatic stress disorder symptoms and absence of harmful effects or drug dependency after 3,4-methylenedioxymethamphetamine-assisted psychotherapy: a prospective long-term follow-up study. J Psychopharmacol 27:28-39.

Mithoefer MC, Grob CS, Brewerton TD (2016) Novel psychopharmacological therapies for psychiatric disorders: psilocybin and MDMA. Lancet Psychiatry 3:481-488.

Mithoefer MC, Feduccia AA, Jerome L, Mithoefer A, Wagner M, Walsh Z, Hamilton S, Yazar-Klosinski B, Emerson A, Doblin R (2019) MDMAassisted psychotherapy for treatment of PTSD: study design and rationale for phase 3 trials based on pooled analysis of six phase 2 randomized controlled trials. Psychopharmacology (Berl) 236:2735-2745.

Moaddel R, Abdrakhmanova G, Kozak J, Jozwiak K, Toll L, Jimenez L, Rosenberg A, Tran T, Xiao Y, Zarate CA, Wainer IW (2013) Sub-anesthetic concentrations of (R,S)-ketamine metabolites inhibit acetylcholineevoked currents in alpha7 nicotinic acetylcholine receptors. Eur J Pharmacol 698:228-234.

Moda-Sava RN, Murdock MH, Parekh PK, Fetcho RN, Huang BS, Huynh TN, Witztum J, Shaver DC, Rosenthal DL, Alway EJ, Lopez K, Meng Y, Nellissen L, Grosenick L, Milner TA, Deisseroth K, Bito H, Kasai H, Liston C (2019) Sustained rescue of prefrontal circuit dysfunction by antidepressant-induced spine formation. Science 364:eaat8078.

Monteggia LM, Kavalali ET (2013) Scopolamine and ketamine: evidence of convergence? Biol Psychiatry 74:712-713.

Morley KC, Arnold JC, McGregor IS (2005) Serotonin (1A) receptor involvement in acute 3,4-methylenedioxymethamphetamine (MDMA) facilitation of social interaction in the rat. Prog Neuropsychopharmacol Biol Psychiatry 29:648-657.

Morris PJ, Moaddel R, Zanos P, Moore CE, Gould TD, Zarate CA Jr, Thomas CJ (2017) Synthesis and N-methyl-d-aspartate (NMDA) receptor activity of ketamine metabolites. Org Lett 19:4572-4575.

Mueller F, Lenz C, Dolder PC, Harder S, Schmid Y, Lang UE, Liechti ME, Borgwardt S (2017) Acute effects of LSD on amygdala activity during processing of fearful stimuli in healthy subjects. Transl Psychiatry 7: e1084

Muller F, Lenz C, Dolder P, Lang U, Schmidt A, Liechti M, Borgwardt S (2017) Increased thalamic resting-state connectivity as a core driver of LSD-induced hallucinations. Acta Psychiatr Scand 136:648-657.

Muller F, Dolder PC, Schmidt A, Liechti ME, Borgwardt S (2018) Altered network hub connectivity after acute LSD administration. Neuroimage Clin 18:694-701.

Multidisciplinary Association for Psychedelic Studies (2018) https://maps.org/ news/media/7466-press-release-participant-screening-begins-in-phase3-clinical-trials-of-mdma-assisted-psychotherapy-for-ptsd.

Multi-Site Phase 3 Study of MDMA-Assisted Psychotherapy for PTSD (2020) https://clinicaltrials.gov/ct2/show/NCT03537014?term=MDMA+ $\% 22 \mathrm{Phase}+3 \% 22 \&$ cond $=\mathrm{PTSD} \& \mathrm{draw}=2 \& \mathrm{rank}=1$.

Murrough JW, Perez AM, Pillemer S, Stern J, Parides MK, aan het Rot M, Collins KA, Mathew SJ, Charney DS, Iosifescu DV (2013a) Rapid and longer-term antidepressant effects of repeated ketamine infusions in treatment-resistant major depression. Biol Psychiatry 74:250-256.

Murrough JW, Iosifescu DV, Chang LC, Al Jurdi RK, Green CE, Perez AM, Iqbal S, Pillemer S, Foulkes A, Shah A, Charney DS, Mathew SJ (2013b) 
Antidepressant efficacy of ketamine in treatment-resistant major depression: a two-site randomized controlled trial. Am J Psychiatry 170:11341142.

Muthukumaraswamy SD, Carhart-Harris RL, Moran RJ, Brookes MJ, Williams TM, Errtizoe D, Sessa B, Papadopoulos A, Bolstridge M, Singh KD, Feilding A, Friston KJ, Nutt DJ (2013) Broadband cortical desynchronization underlies the human psychedelic state. J Neurosci 33:15171-15183.

Nardou R, Lewis EM, Rothhaas R, Xu R, Yang A, Boyden E, Dölen G (2019) Oxytocin-dependent reopening of a social reward learning critical period with MDMA. Nature 569:116-120.

Nichols DE (1986) Differences between the mechanism of action of MDMA, $\mathrm{MBDB}$, and the classic hallucinogens. Identification of a new therapeutic class: entactogens. J Psychoactive Drugs 18:305-313.

Nichols DE (2004) Hallucinogens. Pharmacol Ther 101:131-181.

Nichols DE (2016) Psychedelics. Pharmacol Rev 68:264-355.

Niciu MJ, Shovestul BJ, Jaso BA, Farmer C, Luckenbaugh DA, Brutsche NE, Park LT, Ballard ED, Zarate CA (2018) Features of dissociation differentially predict antidepressant response to ketamine in treatment-resistant depression. J Affect Disord 232:310-315.

Nutt DJ, King LA, Nichols DE (2013) Effects of Schedule I drug laws on neuroscience research and treatment innovation. Nat Rev Neurosci 14:577585.

Palhano-Fontes F, Andrade KC, Tofoli LF, Santos AC, Crippa JA, Hallak JE, Ribeiro S, de Araujo DB (2015) The psychedelic state induced by ayahuasca modulates the activity and connectivity of the default mode network. PLoS One 10:e0118143.

Pallavicini C, Vilas MG, Villarreal M, Zamberlan F, Muthukumaraswamy S, Nutt D, Carhart-Harris R, Tagliazucchi E (2019) Spectral signatures of serotonergic psychedelics and glutamatergic dissociatives. Neuroimage 200:281-291.

Passie T, Seifert J, Schneider U, Emrich HM (2002) The pharmacology of psilocybin. Addict Biol 7:357-364.

Passie T, Halpern JH, Stichtenoth DO, Emrich HM, Hintzen A (2008) The pharmacology of lysergic acid diethylamide: a review. CNS Neurosci Ther 14:295-314.

Paul RK, Singh NS, Khadeer M, Moaddel R, Sanghvi M, Green CE, O'Loughlin K, Torjman MC, Bernier M, Wainer IW (2014) (R,S)Ketamine metabolites (R,S)-norketamine and (2S,6S)-hydroxynorketamine increase the mammalian target of rapamycin function. Anesthesiology 121:149-159.

Pham TH, Defaix C, Xu X, Deng SX, Fabresse N, Alvarez JC, Landry DW, Brachman RA, Denny CA, Gardier AM (2018) Common neurotransmission recruited in $(\mathrm{R}, \mathrm{S})$-ketamine and $(2 \mathrm{R}, 6 \mathrm{R})$-hydroxynorketamineinduced sustained antidepressant-like effects. Biol Psychiatry 84:e3-e6.

Phillips JL, Norris S, Talbot J, Hatchard T, Ortiz A, Birmingham M, Owoeye O, Batten LA, Blier P (2020) Single and repeated ketamine infusions for reduction of suicidal ideation in treatment-resistant depression. Neuropsychopharmacology 45:606-612.

Pitts EG, Minerva AR, Chandler EB, Kohn JN, Logun MT, Sulima A, Rice KC, Howell LL (2017) 3,4-Methylenedioxymethamphetamine increases affiliative behaviors in squirrel monkeys in a serotonin $2 \mathrm{~A}$ receptor-dependent manner. Neuropsychopharmacology 42:1962-1971.

Preller KH, Burt JB, Ji JL, Schleifer CH, Adkinson BD, Stampfli P, Seifritz E, Repovs G, Krystal JH, Murray JD, Vollenweider FX, Anticevic A (2018) Changes in global and thalamic brain connectivity in LSD-induced altered states of consciousness are attributable to the 5-HT2A receptor. Elife 7:e35082.

Preller KH, Razi A, Zeidman P, Stampfli P, Friston KJ, Vollenweider FX (2019) Effective connectivity changes in LSD-induced altered states of consciousness in humans. Proc Natl Acad Sci USA 116:2743-2748.

Preller KH, Duerler P, Burt JB, Ji JL, Adkinson B, Stampfli P, Seifritz E, Repovs G, Krystal JH, Murray JD, Anticevic A, Vollenweider FX (2020) Psilocybin induces time-dependent changes in global functional connectivity. Biol Psychiatry 88:197-207.

Price RB, Nock MK, Charney DS, Mathew SJ (2009) Effects of intravenous ketamine on explicit and implicit measures of suicidality in treatment-resistant depression. Biol Psychiatry 66:522-526.

Price RB, Iosifescu DV, Murrough JW, Chang LC, Al Jurdi RK, Iqbal SZ, Soleimani L, Charney DS, Foulkes AL, Mathew SJ (2014) Effects of ketamine on explicit and implicit suicidal cognition: a randomized controlled trial in treatment-resistant depression. Depress Anxiety 31:335-343.
Psychological Effects of Methylenedioxymethamphetamine (MDMA) When Administered to Healthy Volunteers (2020) https://clinicaltrials.gov/ct2/ show $/$ NCT01404754?term $=$ MDMA $+\% 22$ Phase $+1 \% 22 \&$ draw $=2 \&$ rank $=2$.

Ramos L, Hicks C, Caminer A, Couto K, Narlawar R, Kassiou M, McGregor IS (2016) MDMA ('Ecstasy'), oxytocin and vasopressin modulate social preference in rats: a role for handling and oxytocin receptors. Pharmacol Biochem Behav 150:115-123.

Ricaurte GA, Yuan J, Hatzidimitriou G, Cord BJ, McCann UD (2002) Severe dopaminergic neurotoxicity in primates after a common recreational dose regimen of MDMA ("ecstasy"). Science 297:2260-2263.

Ricaurte GA, Yuan J, Hatzidimitriou G, Cord BJ, McCann UD (2003) Retraction. Science 301:1479.

Rickli A, Luethi D, Reinisch J, Buchy D, Hoener MC, Liechti ME (2015) Receptor interaction profiles of novel N-2-methoxybenzyl (NBOMe) derivatives of 2,5-dimethoxy-substituted phenethylamines (2C drugs). Neuropharmacology 99:546-553.

Rickli A, Moning OD, Hoener MC, Liechti ME (2016) Receptor interaction profiles of novel psychoactive tryptamines compared with classic hallucinogens. Eur Neuropsychopharmacol 26:1327-1337.

Roseman L, Demetriou L, Wall MB, Nutt DJ, Carhart-Harris RL (2018) Increased amygdala responses to emotional faces after psilocybin for treatment-resistant depression. Neuropharmacology 142:263-269.

Rothman RB, Baumann MH (2002) Therapeutic and adverse actions of serotonin transporter substrates. Pharmacol Ther 95:73-88.

Sanacora G, Johnson MR, Khan A, Atkinson SD, Riesenberg RR, Schronen JP, Burke MA, Zajecka JM, Barra L, Su HL, Posener JA, Bui KH, Quirk MC, Piser TM, Mathew SJ, Pathak S (2017) Adjunctive lanicemine (AZD6765) in patients with major depressive disorder and history of inadequate response to antidepressants: a randomized, placebo-controlled study. Neuropsychopharmacology 42:844-853.

Saxton RA, Sabatini DM (2017) mTOR signaling in growth, metabolism, and disease. Cell 169:361-371.

Schatzberg AF (2014) A word to the wise about ketamine. Am J Psychiatry $171: 262-264$

Schenberg EE, Alexandre JF, Filev R, Cravo AM, Sato JR, Muthukumaraswamy SD, Yonamine M, Waguespack M, Lomnicka I, Barker SA, da Silveira DX (2015) Acute biphasic effects of ayahuasca. PLoS One 10:e137202.

Schmid CL, Raehal KM, Bohn LM (2008) Agonist-directed signaling of the serotonin $2 \mathrm{~A}$ receptor depends on $\beta$-arrestin-2 interactions in vivo. Proc Natl Acad Sci USA 105:1079-1084.

Sessa B (2011) Could MDMA be useful in the treatment of PTSD? Prog Neurol Psychiatry 15:4-7.

Sessa B (2018) Why MDMA therapy for alcohol use disorder? And why now? Neuropharmacology 142:83-88.

Sessa B, Sakal C, O'Brien S, Nutt D (2019) First study of safety and tolerability of 3,4-methylenedioxymethamphetamine (MDMA)-assisted psychotherapy in patients with alcohol use disorder: preliminary data on the first four participants. BMJ Case Rep 12:e230109.

Shiroma PR, Thuras P, Wels J, Albott CS, Erbes C, Tye S, Lim KO (2020) A randomized, double-blind, active placebo-controlled study of efficacy, safety, and durability of repeated vs single subanesthetic ketamine for treatment-resistant depression. Transl Psychiatry 10:1-9.

Shulgin AN (1978) Characterization of three new psychomimetics. In: The pharmacology of hallucinogens (Stillman RC, ed). New York: Pergamon.

Singh JB, Fedgchin M, Daly EJ, De Boer P, Cooper K, Lim P, Pinter C, Murrough JW, Sanacora G, Shelton RC, Kurian B, Winokur A, Fava M, Manji H, Drevets WC, Van Nueten L (2016) A double-blind, randomized, placebo-controlled, dose-frequency study of intravenous ketamine in patients with treatment-resistant depression. Am J Psychiatry $173: 816-826$.

Sonenberg N, Hinnebusch AG (2009) Regulation of translation initiation in eukaryotes: mechanisms and biological targets. Cell 136:731-745.

Suzuki K, Nosyreva E, Hunt KW, Kavalali ET, Monteggia LM (2017) Effects of a ketamine metabolite on synaptic NMDAR function. Nature 546:E1-E3.

Timmermann C, Roseman L, Schartner M, Milliere R, Williams LT, Erritzoe D, Muthukumaraswamy S, Ashton M, Bendrioua A, Kaur O, Turton S, Nour MM, Day CM, Leech R, Nutt DJ, Carhart-Harris RL (2019) Neural correlates of the DMT experience assessed with multivariate EEG. Sci Rep 9:16324.

Valle M, Maqueda AE, Rabella M, Rodriguez-Pujadas A, Antonijoan RM, Romero S, Alonso JF, Mananas A, Barker S, Friedlander P, Feilding A, 
Riba J (2016) Inhibition of alpha oscillations through serotonin-2A receptor activation underlies the visual effects of ayahuasca in humans. Eur Neuropsychopharmacol 26:1161-1175.

Vigo DV, Kestel D, Pendakur K, Thornicroft G, Atun R (2019) Disease burden and government spending on mental, neurological, and substance use disorders, and self-harm: cross-sectional, ecological study of health system response in the Americas. Lancet Public Health 4:e89-e96.

Vollenweider FX, Geyer MA (2001) A systems model of altered consciousness: integrating natural and drug-induced psychoses. Brain Res Bull 56:495-507.

Vollenweider FX, Kometer M (2010) The neurobiology of psychedelic drugs: implications for the treatment of mood disorders. Nat Rev Neurosci 11:642-651.

Vollenweider FX, Csomor PA, Knappe B, Geyer MA, Quednow BB (2007) The effects of the preferential 5-HT2A agonist psilocybin on prepulse inhibition of startle in healthy human volunteers depend on interstimulus interval. Neuropsychopharmacology 32:1876-1887.

Wacker D, Wang S, McCorvy JD, Betz RM, Venkatakrishnan AJ, Levit A, Lansu K, Schools ZL, Che T, Nichols DE, Shoichet BK, Dror RO, Roth BL (2017) Crystal structure of an LSD-bound human serotonin receptor. Cell 168:377-389.e312.

Walsh JJ, Christoffel DJ, Heifets BD, Ben-Dor GA, Selimbeyoglu A, Hung LW, Deisseroth K, Malenka RC (2018) 5-HT release in nucleus accumbens rescues social deficits in mouse autism model. Nature 560:589-594.

Whiteford HA, Degenhardt L, Rehm J, Baxter AJ, Ferrari AJ, Erskine HE, Charlson FJ, Norman RE, Flaxman AD, Johns N, Burstein R, Murray CJ, Vos T (2013) Global burden of disease attributable to mental and substance use disorders: findings from the Global Burden of Disease Study 2010. Lancet 382:1575-1586.

Wilkinson ST, Sanacora G (2019) A new generation of antidepressants: an update on the pharmaceutical pipeline for novel and rapid-acting therapeutics in mood disorders based on glutamate/GABA neurotransmitter systems. Drug Discov Today 24:606-615.

Williams NR, Heifets BD, Blasey C, Sudheimer K, Pannu J, Pankow H, Hawkins J, Birnbaum J, Lyons DM, Rodriguez CI, Schatzberg AF (2018) Attenuation of antidepressant effects of ketamine by opioid receptor antagonism. Am J Psychiatry 175:1205-1215.

Wittchen HU, Jacobi F, Rehm J, Gustavsson A, Svensson M, Jönsson B, Olesen J, Allgulander C, Alonso J, Faravelli C, Fratiglioni L, Jennum P, Lieb R, Maercker A, van Os J, Preisig M, Salvador-Carulla L, Simon R, Steinhausen HC (2011) The size and burden of mental disorders and other disorders of the brain in Europe 2010. Eur Neuropsychopharmacol 21:655-679.

Workman ER, Niere F, Raab-Graham KF (2018) Engaging homeostatic plasticity to treat depression. Mol Psychiatry 23:26-35.
Yang C, Hu YM, Zhou ZQ, Zhang GF, Yang JJ (2013) Acute administration of ketamine in rats increases hippocampal BDNF and mTOR levels during forced swimming test. Ups J Med Sci 118:3-8.

Yang C, Qu Y, Abe M, Nozawa D, Chaki S, Hashimoto K (2017) (R)Ketamine shows greater potency and longer lasting antidepressant effects than its metabolite (2R,6R)-hydroxynorketamine. Biol Psychiatry 82:e43e44.

Yang C, Ren Q, Qu Y, Zhang JC, Ma M, Dong C, Hashimoto K (2018a) Mechanistic target of rapamycin-independent antidepressant effects of (R)-ketamine in a social defeat stress model. Biol Psychiatry 83:18-28.

Yang Y, Cui Y, Sang K, Dong Y, Ni Z, Ma S, Hu H (2018b) Ketamine blocks bursting in the lateral habenula to rapidly relieve depression. Nature 554:317-322.

Young M, Andero R, Ressler K, Howell L (2015) 3,4-Methylenedioxymethamphetamine facilitates fear extinction learning. Transl Psychiatry 5:e634.

Young MB, Norrholm SD, Khoury LM, Jovanovic T, Rauch SA, Reiff CM, Dunlop BW, Rothbaum BO, Howell LL (2017) Inhibition of serotonin transporters disrupts the enhancement of fear memory extinction by 3,4methylenedioxymethamphetamine (MDMA). Psychopharmacology (Berl) 234:2883-2895.

Zanos P, Gould TD (2018) Mechanisms of ketamine action as an antidepressant. Mol Psychiatry 23:801-811.

Zanos P, Moaddel R, Morris PJ, Georgiou P, Fischell J, Elmer GI, Alkondon M, Yuan P, Pribut HJ, Singh NS, Dossou KS, Fang Y, Huang XP, Mayo CL, Wainer IW, Albuquerque EX, Thompson SM, Thomas CJ, Zarate CA Jr, Gould TD (2016) NMDAR inhibition-independent antidepressant actions of ketamine metabolites. Nature 533:481-486.

Zanos P, Moaddel R, Morris PJ, Georgiou P, Fischell J, Elmer GI, Alkondon M, Yuan P, Pribut HJ, Singh NS, Dossou KS, Fang Y, Huang XP, Mayo CL, Albuquerque EX, Thompson SM, Thomas CJ, Zarate CA, Gould TD (2017) Zanos et al. reply. Nature 546:E4-E5.

Zarate CA Jr, Singh JB, Carlson PJ, Brutsche NE, Ameli R, Luckenbaugh DA, Charney DS, Manji HK (2006a) A randomized trial of an N-methyl-Daspartate antagonist in treatment-resistant major depression. Arch Gen Psychiatry 63:856-864.

Zarate CA Jr, Singh JB, Quiroz JA, De Jesus G, Denicoff KK, Luckenbaugh DA, Manji HK, Charney DS (2006b) A double-blind, placebo-controlled study of memantine in the treatment of major depression. Am J Psychiatry 163:153-155.

Zhang K, Yamaki VN, Wei Z, Zheng Y, Cai X (2017) Differential regulation of GluAl expression by ketamine and memantine. Behav Brain Res 316:152-159.

Zhou W, Wang N, Yang C, Li XM, Zhou ZQ, Yang JJ (2014) Ketamineinduced antidepressant effects are associated with AMPA receptorsmediated upregulation of mTOR and BDNF in rat hippocampus and prefrontal cortex. Eur Psychiatry 29:419-423. 